\title{
Diversidade de angiospermas e espécies medicinais de uma área de Cerrado
}

SILVA, A.F. ${ }^{*} ;$ RABELO, M.F.R. ${ }^{2}$; ENOQUE, M.M. ${ }^{1}$

'Empresa de Pesquisa Agropecuária de Minas Gerais, Herbário PAMG, Av. José Cândido da Silveira, 1647, Belo Horizonte, MG, 31170-495, ²Brandt Meio Ambiente, Alameda Ingá, 89, Nova Lima, MG, 34000-000. *Autor para correspondência: andreiasilva@epamig.br

RESUMO: Este trabalho teve como objetivo conhecer a diversidade vegetal de uma área de Cerrado em Prudente de Morais, MG, bem como suas indicações medicinais. Foram feitas nove excursões à reserva da Fazenda Experimental Santa Rita da Empresa de Pesquisa

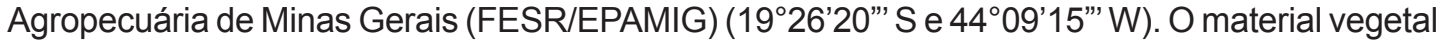
coletado foi herborizado, identificado e incorporado ao acervo do Herbário PAMG/EPAMIG. O sistema de classificação utilizado foi o APG III. Após a identificação, realizou-se uma pesquisa bibliográfica buscando dados sobre a utilização medicinal das espécies. Coletaram-se 108 espécies pertencentes a 47 famílias. As famílias mais representativas foram: Fabaceae, com 16 espécies, Myrtaceae com sete espécies, Asteraceae e Rubiaceae com seis espécies cada, Malpighiaceae e Solanaceae com cinco espécies cada, Erythroxylaceae, Euphorbiaceae e Vochysiaceae, com quatro espécies cada, Anacardiaceae, Apocynaceae, Lamiaceae e Sapindaceae com três espécies cada, Annonaceae, Arecaceae, Bignoniaceae, Celastraceae e Primulaceae com duas espécies cada. Vinte e nove famílias foram monoespecíficas. Das 108 espécies, 39 são árvores (36\%), 43 arbustos (40\%), seis subarbustos (5,5\%), 14 lianas $(13 \%)$ e seis são ervas $(5,5 \%)$. Sessenta e seis $(61 \%)$ espécies pertencentes a 39 famílias (83\%) são utilizadas popularmente, para o tratamento de alguma doença. As famílias com maior número de espécies medicinais foram: Fabaceae com oito espécies; Rubiaceae com cinco espécies e Solanaceae com quatro espécies. As espécies que apresentaram mais finalidades terapêuticas foram: Brosimum gaudichaudii Trécul (Moraceae), Caryocar brasiliense Cambess. (Caryocaraceae), Cochlospermum regium (Mart. ex Schrank) Pilg. (Bixaceae), Croton urucurana Bail. (Euphorbiaceae), Gomphrena officinalis Mart. (Amaranthaceae), Hymenaea stigonocarpa Mart. ex Hayne (Fabaceae), Lithrea molleoides (Vell.) Engl. (Anacardiaceae), Myracrodruon urundeuva Allemão (Anacardiaceae) e Randia. armata (Sw.) DC. (Rubiaceae). As finalidades terapêuticas que apresentaram maior número de espécies foram: tônico (15 spp., 22,7\%), afecções do aparelho respiratório (13 spp., 19,6\%), afecções da pele (12 spp., 18\%) e febres (12 spp., 18\%). O conhecimento tradicional sobre as plantas medicinais do cerrado deve ser mais investigado para que seja preservado, valorizado, e para que medidas conservacionistas sejam tomadas evitando que essas plantas desapareçam antes que sua utilização tradicional seja corroborada pela ciência.

Palavras-chave: Plantas medicinais, diversidade vegetal, etnofarmacologia

ABSTRACT: Angiosperm diversity and medicinal species of Cerrado area. This study aimed to investigate the plant diversity of a Cerrado area in Prudente de Morais, MG, and its medicinal indications. Nine field trips were made to the reserve of Fazenda Experimental Santa Rita of the Empresa de Pesquisa Agropecuária de Minas Gerais (FESR/EPAMIG) (19²6'20" $S$ and $\left.44^{\circ} 09^{\prime} 15^{\prime \prime} \mathrm{W}\right)$. The plant material collected was herborized, identified and incorporated into the collection of the Herbarium PAMG/EPAMIG. The classification system used was the APG III. After identification, we carried out a literature search to find data about the medical use of the species. 108 species were collected, belonging to 47 families. The most representative families were Fabaceae, with 16 species, Myrtaceae with seven species, Asteraceae and Rubiaceae with six species each, Malpighiaceae and Solanaceae with five species each, Erythroxylaceae, Euphorbiaceae and Vochysiaceae, with four species each, Anacardiaceae, Apocynaceae, Lamiaceae and Sapindaceae with three species each, Annonaceae, Arecaceae, Bignoniaceae, Celastraceae and Primulaceae with two species each. Twenty-nine families 
were monoespecific. From the 108 species, 39 are trees (36\%), 43 are shrubs (40\%), six are subshrubs $(5.5 \%), 14$ are climbing $(13 \%)$ and six are herbs $(5.5 \%)$. Sixty-six $(61 \%)$ species belonging to 39 families $(83 \%)$ are commonly used for the treatment of diseases. The families with the highest number of medicinal species were the Fabaceae with eight species; the Rubiaceae with five species and the Solanaceae with four species. The species showing more therapeutic purposes were: Brosimum gaudichaudii Trécul (Moraceae), Caryocar brasiliense Cambess. (Caryocaraceae), Cochlospermum regium (Mart. Ex Schrank) Pilg. (Bixaceae), Croton urucurana Bail. (Euphorbiaceae), Gomphrena officinalis Mart. (Amaranthaceae), Hymenaea stigonocarpa Mart. ex Hayne (Fabaceae), Lithrea molleoides (Vell.) Engl. (Anacardiaceae), Myracrodruon urundeuva Allemão (Anacardiaceae) and Randia. armata (Sw.) DC. (Rubiaceae). The therapeutic purposes indicated by the highest number of species were: tonic (15 spp., $22.7 \%$ ), diseases of the respiratory system (13 spp., 19.6\%), skin affections (12 spp., 18\%) and fever (12 spp., $18 \%)$. The traditional knowledge of medicinal plants of the Cerrado should be investigated further in order to be preserved and enhanced. In that sense, conservation measures should be taken for these plants do not disappear before their traditional use is supported by science.

Keywords: Medicinal plants, plant diversity, ethnopharmacology

\section{INTRODUÇÃO}

São reconhecidas 45986 espécies para a flora brasileira, sendo 4733 de Algas, 32771 de Angiospermas, 1524 de Briófitas, 5675 de Fungos, 30 de Gimnospermas e 1253 de Samambaias e Licófitas (Jardim Botânico do Rio de Janeiro, 2013), das 264 a 279 mil espécies vegetais conhecidas e catalogadas para o mundo (Peixoto \& Morim, 2003; Giulietti et al., 2005). Ocorrendo 41 famílias e 8.016 espécies incluídas em 669 gêneros de monocotiledôneas, representando $14 \%$ do total mundial. Dessas espécies, 3.557 são endêmicas ao Brasil. Quanto às dicotiledôneas, Shepherd (2003) afirma que existam cerca de 21 mil espécies no Brasil, o que representa $11,3 \%$ da flora do mundo. As famílias Fabaceae (s. I.), Asteraceae, Euphorbiaceae, Myrtaceae e Rubiaceae são as mais famílias diversas em número de espécies no país (Giulietti et al., 2005).

Em termos sociais, o Brasil possui uma sociodiversidade riquíssima, englobando 220 etnias indígenas, além de comunidades locais como quilombolas, seringueiros, caiçaras, etc. que detêm importantes conhecimentos tradicionais associados à biodiversidade (Brasil, 2014).

A diversidade biológica de qualquer nação tem que ser tratada como um recurso global, para ser registrada, usada e, acima de tudo, preservada (Wilson, 1997). Essa afirmativa toma um caráter urgente, considerando que o crescimento explosivo das populações humanas está desgastando o meio ambiente de forma acelerada, a ciência está descobrindo novas utilizações para a diversidade biológica e grande parte desta está se perdendo irreversivelmente pela destruição de habitat naturais (Ehrlich, 1997; Wilson, 1997; Calixto, 2000).

Minas Gerais ocupa cerca de $7 \%$ do território nacional (Drummond et al., 2005). Possui relevo variado e fortemente acidentado em algumas porções, destacando-se elevações expressivas como as serras da Mantiqueira, do Espinhaço e do Caparaó (Martins, 2000). A vasta superfície, o clima, a diversidade de relevos, os recursos hídricos, além das características do solo, garantem paisagens diferenciadas, com ambientes específicos e uma rica cobertura vegetal, que pode ser dividida em três biomas: Cerrado, Mata Atlântica e Caatinga (Drummond et al., 2005). Em termos de diversidade vegetal, Minas Gerais possui 11575 espécies de 195 famílias de angiospermas distribuídas por esses biomas (Jardim Botânico do Rio de Janeiro, 2013).

O Cerrado é um complexo vegetacional, onde inclui-se: campo limpo, campo sujo, campo cerrado, cerrado propriamente dito e o cerradão (Floresta Mesófila Esclerófila), além das inclusões de mata ciliar, mata seca (Floresta Mesófila Estacional), veredas ou buritizais e campos rupestres (Mendonça et al., 1998; Brandão et al., 2001). Este bioma, é o segundo maior do país em área, só perdendo para a Amazônia (Ratter et al., 1997; Klink \& Machado, 2005). Somente 2,2\% do bioma estão legalmente protegidos e estimativas indicam que pelo menos $20 \%$ das espécies endêmicas e ameaçadas permanecem fora dos parques e reservas existentes (Klink \& Machado, 2005). Segundo Ratter et al. (1997), o Cerrado é um dos biomas mais ameaçados pelo avanço das atividades agropecuárias. No período de 1978 a 1988, o desmatamento médio no Cerrado foi de $40.000 \mathrm{~km}^{2}$ por ano (Klink \& Moreira, 2002). Assim, o Cerrado é considerado um hotspot, ou seja, está entre as regiões do mundo com a biodiversidade mais ameaçada de extinção (Henriques, 2003; Klink \& Machado, 2005).

As transformações ocorridas no Cerrado

Rev. Bras. PI. Med., Campinas, v.17, n.4, supl. III, p.1016-1030, 2015. 
trouxeram grandes danos ambientais: fragmentação de habitat, extinção da biodiversidade, invasão de espécies exóticas, erosão dos solos, poluição de aquíferos, degradação de ecossistemas, alterações nos regimes de queimadas, desequilíbrios no ciclo do carbono e modificações climáticas regionais (Klink \& Moreira, 2002).

Tendo em vista a grande biodiversidade do país, especialmente de Minas Gerais, as pressões sofridas pelos biomas e pelas comunidades tradicionais, seja pela modernização ou pelas mudanças no estilo de vida tradicional para mais contemporâneo, há uma necessidade urgente, de conhecer espécies da flora e seu uso na medicina tradicional, principalmente o relacionado à utilização de plantas selvagens. Sendo assim, neste trabalho buscou-se ampliar o conhecimento sobre a diversidade florística do Cerrado de Minas Gerais, obtendo-se informações sobre as utilizações medicinais das espécies.

\section{MATERIAL E MÉTODO}

A área de Cerrado desse estudo está localizada no município de Prudente de Morais (MG), entre as coordenadas geográficas de $19^{\circ} 26^{\prime} 20^{\prime \prime}$ de Latitude Sul e $44^{\circ} 09^{\prime} 15^{\prime \prime}$ de Longitude Oeste e altitude média de $699 \mathrm{~m}$. Pertence à Fazenda Experimental Santa Rita (FESR), que faz parte do Centro Tecnológico do Centro Oeste (CTCO) da Empresa de Pesquisa Agropecuária de Minas Gerais (EPAMIG). A Fazenda possui área de 604ha, dos quais, 120 ha compõem sua reserva biológica.

Foram feitas nove excursões à reserva da FESR, onde se percorreram trilhas aleatórias préexistentes, e foram coletados exemplares da flora fanerogâmica que se apresentavam em estádio reprodutivo, visando facilitar a identificação. As plantas foram georreferenciadas, utilizando-se um aparelho de GPS, possibitando a recoleta. Os espécimes foram herborizados segundo técnicas descritas por Fidalgo \& Bononi (1984). As plantas foram identificadas utilizando-se bibliografia específica; por meio de comparação com exemplares existentes no acervo do Herbário PAMG da EPAMIG e do Herbário BHCB da Universidade Federal de Minas Gerais (UFMG); e, por consultas a taxonomistas especialistas nas diversas famílias botânicas. As espécies foram classificadas quanto ao hábito, seguindo as definições propostas por Vidal \& Vidal (1986). O sistema de classificação utilizado foi o "Angiosperm Phylogeny Group III" (APG III, 2009) (Souza \& Lorenzi, 2012). A nomenclatura foi conferida seguindo a Lista de Espécies da Flora do Brasil (Jardim Botânico do Rio de Janeiro, 2013).

As plantas foram fotografadas no local da coleta e as exsicatas produzidas foram registradas e incorporadas ao acervo do Herbário PAMG/EPAMIG. Após a identificação das plantas coletadas foi realizada uma revisão bibliográfica referente à utilização medicinal de cada uma das espécies. Nessa revisão foram utilizados dicionários de plantas medicinais como Corrêa (1984), levantamentos florísticos de espécies vegetais úteis do Cerrado como Almeida et al. (1998) e de plantas medicinais como Brandão (1991), Vieira \& Martins (2000), Rodrigues \& Carvalho (2001), Rodrigues \& Carvalho (2010), entre outros.

\section{RESULTADO E DISCUSSÃO Diversidade}

Foram feitas nove excursões à Reserva da Fazenda Experimental Santa Rita em Prudente de Morais, onde foram coletadas 108 espécies vegetais pertencentes 47 famílias (Tabela 1). As famílias mais representativas foram: Fabaceae, com 16 espécies, Myrtaceae com sete espécies, Asteraceae e Rubiaceae com seis espécies cada, Malpighiaceae e Solanaceae, com cinco espécies cada, Erythroxylaceae, Euphorbiaceae e Vochysiaceae, com quatro espécies cada, Anacardiaceae, Apocynaceae, Lamiaceae e Sapindaceae com três espécies cada, Annonaceae, Arecaceae, Bignoniaceae, Celastraceae e Primulaceae com duas espécies cada, as famílias Amaranthaceae, Araliaceae, Bixaceae, Calophyllaceae, Cannabaceae, Caryocaraceae, Cleomaceae, Combretaceae, Connaraceae, Convolvulaceae, Cyperaceae, Dilleniaceae, Haloragaceae, Loranthaceae, Lythraceae, Malvaceae, Meliaceae, Moraceae, Nyctaginaceae, Orchidaceae, Poaceae, Proteaceae, Santalaceae, Sapotaceae, Smilacaceae, Styracaceae, Verbernaceae e Vitaceae foram monoespecíficas. Somente um táxon foi identificado apenas ao nível de gênero (Diplopterys sp. - Família Malpighiaceae) (Tabela 1).

Os dados das famílias mais diversas da área estão de acordo com os levantamentos florísticos feitos para o mesmo bioma. Segundo Giulietti et al. (2005), as famílias Fabaceae (3200 spp.), Asteraceae (1900 spp.), Euphorbiaceae (1100 spp.), Myrtaceae (1038 spp.) e Rubiaceae (1000 spp.) são as maiores famílias, em número de espécies no Brasil. No bioma Cerrado, a famílias Fabaceae (777 spp.), Asteraceae (557 spp.), Rubiaceae (250 spp.), Melastomataceae (231 spp.) e Myrtaceae (211 spp.) são as mais diversas (Mendonça et al., 1998). Euphorbiaceae, Lauraceae, Melastomataceae, Myrsinaceae e Rubiaceae, aparecem entre as dez famílias de maior número de espécies em estudos em áreas de florestas de galerias em Minas Gerais (Oliveira Filho et al., 1995).

Todas as plantas foram herborizadas

Rev. Bras. PI. Med., Campinas, v.17, n.4, supl. III, p.1016-1030, 2015. 
e registradas (Tabela 1 ), sendo produzidas aproximadamente, 180 exsicatas.

Dentre as espécies encontradas na área de Cerrado em estudo, 39 são árvores (36\%), 43 arbustos (40\%), seis são subarbustos (5,5\%), 14 lianas $(13 \%)$ e seis são ervas $(5,5 \%)$ (Tabela 1$)$. Segundo Castro et al. (1999), o Cerrado abriga cerca de 2.000 espécies arbóreas e 5.250 espécies herbáceas e ou subarbustivas. O maior número de arbóreas encontradas pode estar relacionado com a ocorrência frequente de incêndios, que suprime as espécies herbáceas, mais sensíveis à queimadas constantes. Num levantamento sobre recursos medicinais do cerrado de Mato Grosso, Guarim Neto \& Morais (2003) encontram a maioria de espécies arbóreas (31\%), seguido pelo hábito herbáceo $(24 \%)$, arbustivo (17\%), subarbustivo $(12 \%)$ e trepadeira $(9 \%)$.

TABELA 1. Distribuição das espécies coletadas por família, na área de Cerrado da Fazenda Experimental Santa Rita (FESR), Prudente de Morais, MG, com seus respectivos hábitos e números de registro no Herbário PAMG/EPAMIG

\begin{tabular}{|c|c|c|}
\hline Família Espécie & Hábito & Registro PAMG \\
\hline \multicolumn{3}{|l|}{ Amaranthaceae } \\
\hline Gomphrena officinalis Mart. & Erva & 55881 \\
\hline \multicolumn{3}{|l|}{ Anacardiaceae } \\
\hline Lithrea molleoides (Vell.) Engl. & Árvore & 57011 \\
\hline Myracrodruon urundeuva Allemão & Árvore & 57012 \\
\hline Tapirira guianensis Aubl. & Árvore & $56407 / 56008 / 56407$ \\
\hline \multicolumn{3}{|l|}{ Annonaceae } \\
\hline Annona crassiflora Mart. & Árvore & 44019 \\
\hline Xylopia aromatica (Lam.) Mart. & Árvore & 56580 \\
\hline \multicolumn{3}{|l|}{ Apocynaceae } \\
\hline Aspidosperma tomentosum Mart. & Árvore & $56222 / 56584 / 56698$ \\
\hline Mandevilla scabra (Hoffmanns. ex Roem. \& Schult.) K.Schum. & Liana & 56681 \\
\hline Marsdenia altissima (Jacq.) Dugand & Liana & $52925 / 55890$ \\
\hline \multicolumn{3}{|l|}{ Araliaceae } \\
\hline Schefflera macrocarpa (Cham. \& Schltdl.) Frodin & Árvore & 56678 \\
\hline \multicolumn{3}{|l|}{ Arecaceae } \\
\hline Syagrus flexuosa (Mart.) Becc. & Árvore & 56703 \\
\hline Acrocomia aculeata (Jacq.) Lodd. ex Mart. & Árvore & 1752 (Carpoteca) \\
\hline \multicolumn{3}{|l|}{ Asteraceae } \\
\hline Chresta sphaerocephala DC. & Subarbusto & 56676 \\
\hline Chromolaena chaseae (B.L.Rob.) R.M.King \& H.Rob. & Arbusto & $56670 / 56679$ \\
\hline Lessingianthus ammophilus (Gardner) H.Rob. & Arbusto & 56683 \\
\hline Piptocarpha rotundifolia (Less.) Baker & Arbusto & $56424 / 56573$ \\
\hline Vernonanthura phosphorica (Vell.) H.Rob. & Arbusto & $56403 / 56577 / 56585$ \\
\hline Viguiera robusta Gardner & Subarbusto & $56699 / 56700$ \\
\hline \multicolumn{3}{|l|}{ Bignoniaceae } \\
\hline Tabebuia aurea (Silva Manso) Benth. \& Hook f. ex S.Moore & Árvore & 57014 \\
\hline Zeyheria montana Mart. & Arbusto & 56575 \\
\hline \multicolumn{3}{|l|}{ Bixaceae } \\
\hline Cochlospermum regium (Mart. ex Schrank) Pilg. & Arbusto & 56036 \\
\hline \multicolumn{3}{|l|}{ Calophyllaceae } \\
\hline Kielmeyera coriacea Mart. \& Zucc. & Árvore & $56227 / 56711$ \\
\hline \multicolumn{3}{|l|}{ Cannabaceae } \\
\hline Celtis pubescens (Kunth) Spreng. & Árvore & $56401 / 56434 / 56435$ \\
\hline
\end{tabular}


TABELA 1. Distribuição das espécies coletadas por família, na área de Cerrado da Fazenda Experimental Santa Rita (FESR), Prudente de Morais, MG, com seus respectivos hábitos e números de registro no Herbário PAMG/EPAMIG continuação...

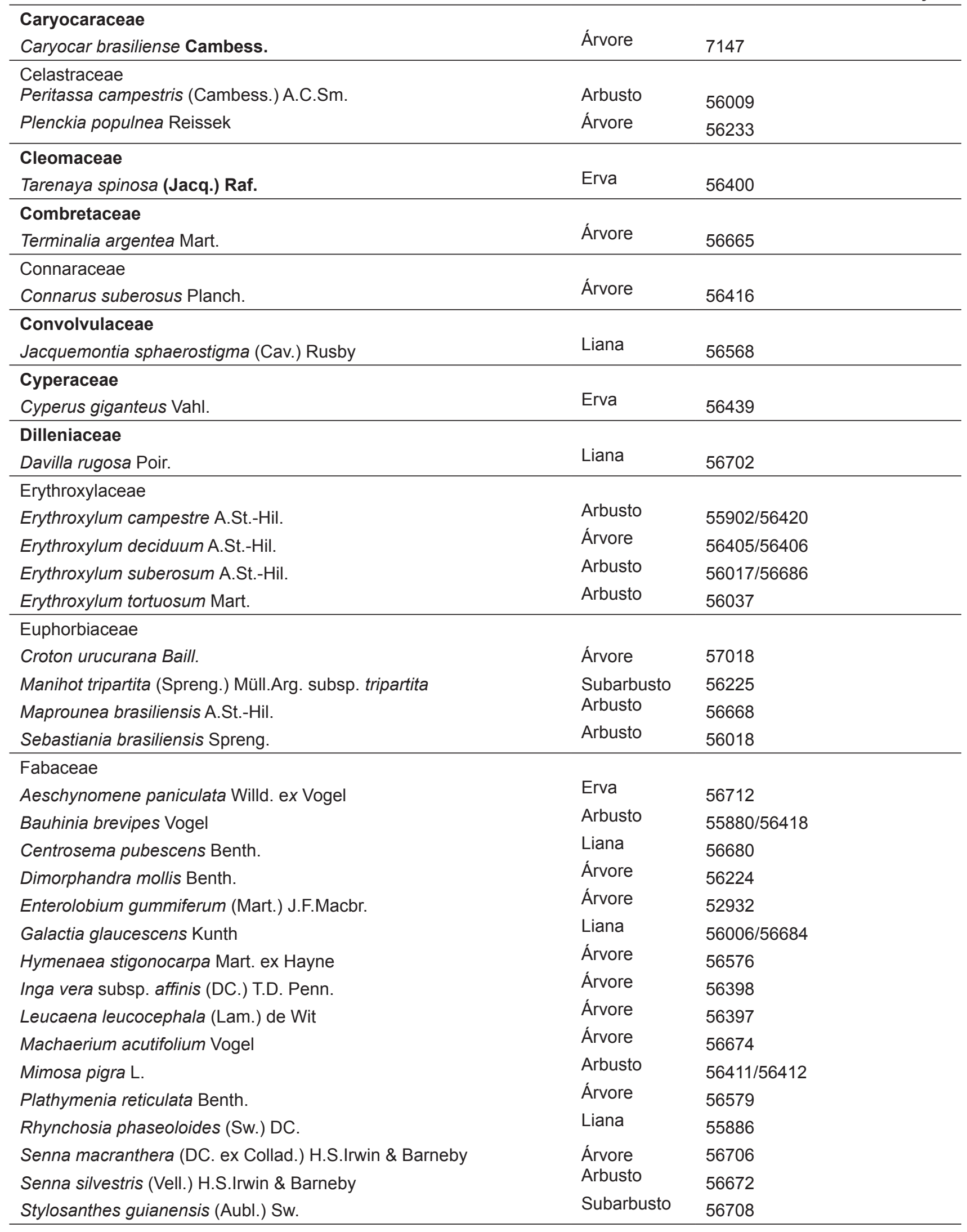


TABELA 1. Distribuição das espécies coletadas por família, na área de Cerrado da Fazenda Experimental Santa Rita (FESR), Prudente de Morais, MG, com seus respectivos hábitos e números de registro no Herbário PAMG/EPAMIG

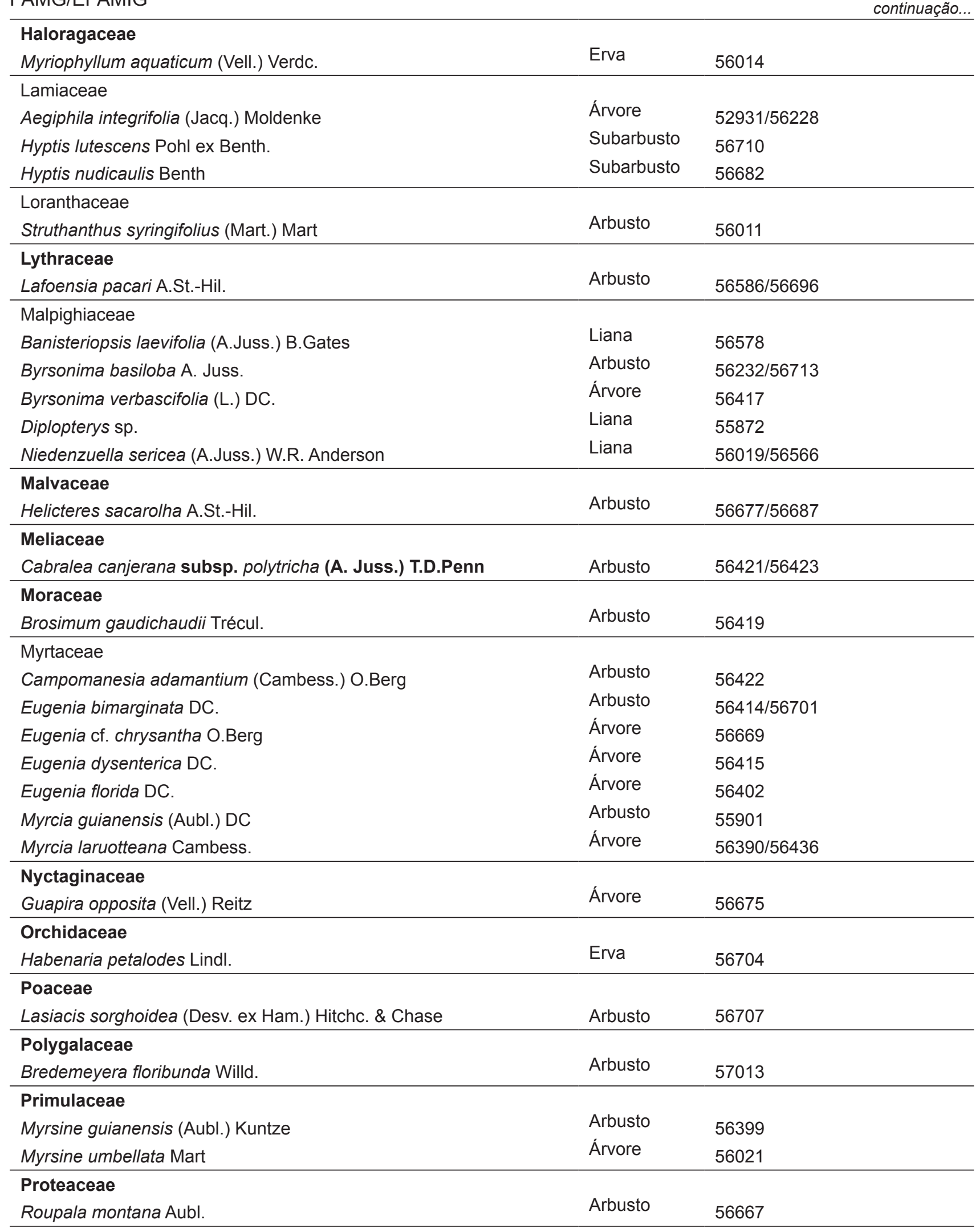


TABELA 1. Distribuição das espécies coletadas por família, na área de Cerrado da Fazenda Experimental Santa Rita (FESR), Prudente de Morais, MG, com seus respectivos hábitos e números de registro no Herbário PAMG/EPAMIG

\begin{tabular}{|c|c|c|}
\hline \multicolumn{3}{|l|}{ Rubiaceae } \\
\hline Cordiera sessilis (Vell.) Kuntze & Arbusto & 56015 \\
\hline Palicourea rigida Kunth & Arbusto & 56571 \\
\hline Psychotria carthagenensis Jacq. & Arbusto & $56410 / 56438$ \\
\hline Randia armata (Sw.) DC. & Arbusto & 56437 \\
\hline Rudgea viburnoides (Cham.) Benth. & Arbusto & 56709 \\
\hline Tocoyena formosa (Cham. \& Schltdl.) K.Schum. & Arbusto & 56583 \\
\hline \multicolumn{3}{|l|}{ Santalaceae } \\
\hline Phoradendron crassifolium (Pohl ex DC.) Eichler & Arbusto & 56408 \\
\hline \multicolumn{3}{|l|}{ Sapindaceae } \\
\hline Magonia pubescens A.St.-Hil. & Árvore & 56673 \\
\hline Paullinia elegans Cambess. & Liana & $56231 / 56587$ \\
\hline Serjania lethalis A.St.-Hil.. & Liana & $55882 / 56013$ \\
\hline \multicolumn{3}{|l|}{ Sapotaceae } \\
\hline Chrysophyllum marginatum (Hook. \& Arn.) Radlk. & Árvore & $52929 / 56404$ \\
\hline \multicolumn{3}{|l|}{ Smilacaceae } \\
\hline Smilax brasiliensis Spreng. & Liana & $52926 / 52933 / 56413$ \\
\hline \multicolumn{3}{|l|}{ Solanaceae } \\
\hline Cestrum axillare Vell. & Arbusto & 57019 \\
\hline Cestrum pedicellatum Sendtn. & Arbusto & $52930 / 56007$ \\
\hline Solanum aculeatissimum Jacq. & Arbusto & 1710 \\
\hline Solanum Iycocarpum A.St.-Hil. & Arbusto & 5840 \\
\hline Solanum scuticum M.Nee & Arbusto & 56409 \\
\hline \multicolumn{3}{|l|}{ Styracaceae } \\
\hline Styrax ferrugineus Nees \& Mart. & Árvore & $52928 / 56034 / 56229 / 56666$ \\
\hline \multicolumn{3}{|l|}{ Verbenaceae } \\
\hline Lantana hypoleuca Briq. & Arbusto & 56705 \\
\hline \multicolumn{3}{|l|}{ Vitaceae } \\
\hline Cissus erosa Rich. & Liana & 56685 \\
\hline \multicolumn{3}{|l|}{ Vochysiaceae } \\
\hline Qualea grandiflora Mart. & Árvore & 56572 \\
\hline Qualea multiflora Mart. & Arbusto & $56569 / 56582 / 56697$ \\
\hline Qualea parviflora Mart. & Arbusto & $55887 / 56671$ \\
\hline Vochysia cinnamomea Pohl & Árvore & 56570 \\
\hline
\end{tabular}

\section{Espécies medicinais}

Dentre as 108 espécies coletadas e identificadas, 66 (61\%) são utilizadas popularmente, para o tratamento de alguma enfermidade (Tabela 2). Segundo Matteucci et al. (1995), muitas espécies do Cerrado, são potencialmente comestíveis, medicinais, ornamentais, fornecedoras de madeira e outras matérias-primas para a indústria.

Das 47 famílias encontradas na reserva da FESR, 39 (83\%) apresentaram pelo menos uma espécie com indicação de uso na medicina popular.
As famílias mais representativas foram: Fabaceae com oito espécies; Rubiaceae com cinco espécies; Solanaceae com quatro espécies; Anacardiaceae, Erythroxylaceae, Euphorbiaceae e Myrtaceae com três espécies cada; Annonaceae, Apocynaceae, Asteraceae, Bignoniaceae e Primulaceae com duas espécies cada; e 27 famílias apresentaram uma espécie medicinal, cada. Segundo Rodrigues \& Carvalho (2010), as famílias Fabaceae e Asteraceae estão entre as mais representativas na maioria dos levantamentos sobre plantas medicinais. Deve-se 
TABELA 2. Espécies coletadas na área de Cerrado da Fazenda Experimental Santa Rita (FESR), Prudente de Morais, MG, com nome (s) popular (es) e indicação na medicina tradicional

\begin{tabular}{|c|c|c|}
\hline Espécie & $\begin{array}{l}\text { Nome (s) } \\
\text { popular (es) }\end{array}$ & Indicação \\
\hline $\begin{array}{l}\text { Aegiphila integrifolia } \\
\text { (Jacq.) Moldenke }\end{array}$ & $\begin{array}{l}\text { Tamaqueiro, } \\
\text { milho-de-grilo, } \\
\text { fruta-de- } \\
\text { papagaio, etc. }\end{array}$ & $\begin{array}{l}\text { As partes aéreas são utilizadas para tratar picadas de cobras e como } \\
\text { antinflamatório (Leitão et al., 1992). }\end{array}$ \\
\hline $\begin{array}{l}\text { Acrocomia aculeata } \\
\text { (Jacq.) Lodd. ex } \\
\text { Mart. }\end{array}$ & $\begin{array}{l}\text { Macauba, coco- } \\
\text { catarro, coco- } \\
\text { babão, etc. }\end{array}$ & $\begin{array}{l}\text { A polpa dos frutos é purgante (Almeida et al., 1998). A polpa e a amêndoa } \\
\text { são utilizadas para tratar dores de cabeça e afecções das vias respiratórias } \\
\text { (Corrêa, 1984). }\end{array}$ \\
\hline $\begin{array}{l}\text { Annona crassiflora } \\
\text { Mart. }\end{array}$ & $\begin{array}{l}\text { Araticum, } \\
\text { articum, etc. }\end{array}$ & $\begin{array}{l}\text { A planta é utilizada como inseticida (Souza \& Felfili, 2006). As sementes são } \\
\text { adstringentes (anti-diarréicas) (Ferreira, 1980; Brandão, 1991; Rodrigues \& } \\
\text { Carvalho, 2001). }\end{array}$ \\
\hline $\begin{array}{l}\text { Aspidosperma } \\
\text { tomentosum Mart. }\end{array}$ & $\begin{array}{l}\text { Peroba, pequiá, } \\
\text { guatambu-do- } \\
\text { campo, etc. }\end{array}$ & $\begin{array}{l}\text { A planta é tônica e febrífuga e utilizada para tratar dispnéia (Valente \& Silva, } \\
\text { 1999). }\end{array}$ \\
\hline $\begin{array}{l}\text { Brosimum } \\
\text { gaudichaudii Trécul. }\end{array}$ & Mamacadela & $\begin{array}{l}\text { As raízes são utilizadas para tratar vitiligo, hepatite, acnes, alergias, fissuras } \\
\text { dérmicas, verminoses, infecções em geral, coluna e viroses de animais; } \\
\text { diurético, depurativo e calmante (Brandão, 1991; Rizzini \& Mors, 1995). }\end{array}$ \\
\hline $\begin{array}{l}\text { Byrsonima } \\
\text { verbascifolia (L.) } \\
\text { DC. }\end{array}$ & Murici & $\begin{array}{l}\text { A casca do caule é utilizada como antifebril e adstringente; os ramos com } \\
\text { folhas contra sífilis e diurética e os frutos são laxantes (Rodrigues \& Carvalho, } \\
\text { 2001). }\end{array}$ \\
\hline $\begin{array}{l}\text { Cabralea canjerana } \\
\text { subsp. polytricha (A. } \\
\text { Juss.) T.D.Penn }\end{array}$ & $\begin{array}{l}\text { Cangerana, } \\
\text { cangerana-do- } \\
\text { campo, etc. }\end{array}$ & A casca é tônica e febrífuga (Ferreira, 1980). \\
\hline $\begin{array}{l}\text { Campomanesia } \\
\text { adamantium } \\
\text { (Cambess.) O.Berg }\end{array}$ & Gabiroba & $\begin{array}{l}\text { As folhas são anti-reumáticas e a raiz colagoga (Ferreira, 1980; Brandão, } \\
\text { 1991). A planta toda é depurativa, anti-diarréica, purificadora, anti-reumática } \\
\text { e para diminuir o colesterol do sangue (Pavan et al., 2009). }\end{array}$ \\
\hline $\begin{array}{l}\text { Caryocar brasiliense } \\
\text { Cambess. }\end{array}$ & $\begin{array}{l}\text { Pequi, } \\
\text { pequizeiro, etc. }\end{array}$ & $\begin{array}{l}\text { A casca e as folhas são adstringentes (Corrêa, 1984). O óleo da castanha e } \\
\text { os caroços são utilizados para tratar asma, bronquite, coqueluche e resfriados. } \\
\text { Os caroços são considerados tônicos e afrodisíacos (Rodrigues \& Carvalho, } \\
\text { 2001). As folhas são adstringentes e estimulam a secreção da bile (Brandão } \\
\text { et al., 1992). }\end{array}$ \\
\hline $\begin{array}{l}\text { Celtis pubescens } \\
\text { (Kunth) Spreng. }\end{array}$ & Grão-de-galo & $\begin{array}{l}\text { A casca tem utilização como febrífugo e externamente contra oftalmia } \\
\text { (Corrêa, 1984). }\end{array}$ \\
\hline $\begin{array}{l}\text { Cestrum axillare } \\
\text { Vell. }\end{array}$ & Coerana & $\begin{array}{l}\text { As folhas são emolientes, sedativas, antiespasmódicas, parasiticidas, } \\
\text { insetífugas, diuréticas e anti-hemorroidárias (Corrêa, 1984). }\end{array}$ \\
\hline $\begin{array}{l}\text { Chysophyllum } \\
\text { marginatum (Hook. } \\
\text { \& Arn.) Radlk. }\end{array}$ & Aguaí & As folhas são utilizadas para tratar afecções cutâneas (Corrêa, 1984). \\
\hline Cissus erosa Rich. & $\begin{array}{l}\text { Cipó-de-fogo e } \\
\text { cafezinho }\end{array}$ & $\begin{array}{l}\text { As partes aéreas são utilizadas, externamente para remover verrugas e tratar } \\
\text { úlceras; internamente, em decocção, para tratar a leishmaniose e como } \\
\text { analgésico (Agra et al., 2007). }\end{array}$ \\
\hline $\begin{array}{l}\text { Cochlospermum } \\
\text { regium (Mart. ex } \\
\text { Schrank) Pilg. }\end{array}$ & $\begin{array}{l}\text { Algodão- } \\
\text { do-campo e } \\
\text { algodãozinho }\end{array}$ & $\begin{array}{l}\text { A raiz é amarga e acre, sendo utilizada para tratar inflamações intestinais, } \\
\text { dores causadas por quedas ou acidentes, maturativa ou dissolvente de } \\
\text { abscessos (Corrêa, 1984), purgativa (Ferreira, 1980). A planta é também } \\
\text { utilizada para tratar inflamações uterinas, das vias urinárias e diarréia (Souza } \\
\text { \& Felfili, 2006). }\end{array}$ \\
\hline $\begin{array}{l}\text { Connarus suberosus } \\
\text { Planch. }\end{array}$ & $\begin{array}{l}\text { Araruta-do- } \\
\text { campo e araribá }\end{array}$ & $\begin{array}{l}\text { A casca é utilizada para tratar cardiopatias e as folhas, problemas intestinais } \\
\text { (Silva Júnior, 2005). }\end{array}$ \\
\hline
\end{tabular}


TABELA 2. Espécies coletadas na área de Cerrado da Fazenda Experimental Santa Rita (FESR), Prudente de Morais, MG, com nome (s) popular (es) e indicação na medicina tradicional

\begin{tabular}{|c|c|c|}
\hline $\begin{array}{l}\text { Cordiera sessilis } \\
\text { (Vell.) Kuntze }\end{array}$ & $\begin{array}{l}\text { Marmelada-de- } \\
\text { cachorro }\end{array}$ & $\begin{array}{l}\text { Os ramos e folhas são utilizados para tratar problemas de pele (Silva et al., } \\
\text { 2007). }\end{array}$ \\
\hline $\begin{array}{l}\text { Croton urucurana } \\
\text { Baill. }\end{array}$ & $\begin{array}{l}\text { Sangra-d'água e } \\
\text { mangue }\end{array}$ & $\begin{array}{l}\text { A planta é utilizada no tratamento do câncer e feridas externas (Souza \& Felfili, } \\
\text { 2006). A seiva da planta é utilizada como anti-hemorrágico, antinflamatório, } \\
\text { antisséptico, antiviral, cicatrizante, hemostática e vulnerária (Lorenzi \& } \\
\text { Matos, 2008). }\end{array}$ \\
\hline $\begin{array}{l}\text { Cyperus giganteus } \\
\text { Vahl. }\end{array}$ & Papiro & O caule é utilizado para tratar bronquite e gripe (Arantes et al., 2003). \\
\hline Davilla rugosa Poir. & Cipó-caboclo & $\begin{array}{l}\text { A raiz é considerada adstringente, sendo tônica, laxativa e sedativa; as folhas } \\
\text { frescas são utilizadas para tratar linfatismo, inchações e orquites; os ramos } \\
\text { jovens são diuréticos (Rodrigues \& Carvalho, 2001). }\end{array}$ \\
\hline $\begin{array}{l}\text { Dimorphandra mollis } \\
\text { Benth. }\end{array}$ & $\begin{array}{l}\text { Faveira-do- } \\
\text { campo e fava- } \\
\text { d'anta }\end{array}$ & $\begin{array}{l}\text { Os frutos são cicatrizantes, provocam contrações uterinas, adstringentes e } \\
\text { tóxicos em altas doses (Ferreira, 1980, Silva Júnior, 2005; Kuhlmann, 2012). }\end{array}$ \\
\hline $\begin{array}{l}\text { Enterolobium } \\
\text { gummiferum (Mart.) } \\
\text { J.F.Macbr. }\end{array}$ & $\begin{array}{l}\text { Orelha-de- } \\
\text { macaco }\end{array}$ & $\begin{array}{l}\text { As folhas, a goma e a seiva são utilizadas para tratar pulmões, dermatites; } \\
\text { a casca é vermífuga (Silva Júnior, 2005). Os frutos são tóxicos para o gado } \\
\text { (Kuhlmann, 2012). }\end{array}$ \\
\hline $\begin{array}{l}\text { Erythroxylum } \\
\text { campestre A.St.-Hil. }\end{array}$ & $\begin{array}{l}\text { Cabeça-de- } \\
\text { negro }\end{array}$ & $\begin{array}{l}\text { A raiz e a casca são purgantes (Corrêa, 1984; (Rodrigues \& Carvalho, 2001). } \\
\text { Possui alcalóides biologicamente ativos com propriedades estimulantes do } \\
\text { sistema nervoso central (Kuhlmann, 2012). }\end{array}$ \\
\hline $\begin{array}{l}\text { Erythroxylum } \\
\text { suberosum A.St.-Hil. }\end{array}$ & $\begin{array}{l}\text { Cabeça-de- } \\
\text { negro e cabelo- } \\
\text { de-negro }\end{array}$ & $\begin{array}{l}\text { A planta possui várias propriedades medicinais, principalmente como } \\
\text { fortificante (Corrêa, 1984), além de ser usada como anestésico e contra a } \\
\text { má digestão (Barbosa et al., 2003). }\end{array}$ \\
\hline $\begin{array}{l}\text { Erythroxylum } \\
\text { tortuosum Mart. }\end{array}$ & $\begin{array}{l}\text { Cabeça-de- } \\
\text { negro e muxiba- } \\
\text { comprida }\end{array}$ & $\begin{array}{l}\text { A casca e o caule são usados como anti-hemorrágicos e a raiz é laxante } \\
\text { (Silva Júnior, 2005). }\end{array}$ \\
\hline $\begin{array}{l}\text { Eugenia dysenterica } \\
\text { DC. }\end{array}$ & Cagaita & $\begin{array}{l}\text { Os frutos são laxantes (Ferreira, 1980). As folhas são utilizadas para tratar } \\
\text { diarréia e desinterias (Agra et al., 2007). }\end{array}$ \\
\hline Eugenia florida DC. & Pitanga-do-mato & As folhas são utilizadas para tratar diarréias (Rodrigues \& Carvalho, 2010). \\
\hline $\begin{array}{l}\text { Gomphrena } \\
\text { officinalis Mart. }\end{array}$ & Paratudo & $\begin{array}{l}\text { A raiz é amarga, aromática, excitante, tônica e febrífuga, útil na debilidade } \\
\text { geral do organismo. O chá e a garrafada com raiz e flor são usados no combate } \\
\text { à febre, asma e bronquite. As flores são usadas contra irregularidades } \\
\text { menstruais e o xilopódio empregado no tratamento das colites e enterites } \\
\text { (Penna, 1946; Barros, 1982). }\end{array}$ \\
\hline $\begin{array}{l}\text { Helicteres sacarolha } \\
\text { A.St.-Hil. }\end{array}$ & $\begin{array}{l}\text { Rosquinha e } \\
\text { sacarrolha. }\end{array}$ & A casca da planta é utilizada para tratar dor no corpo (Guarim Neto, 1987). \\
\hline $\begin{array}{l}\text { Hymenaea } \\
\text { stigonocarpa Mart. } \\
\text { ex Hayne }\end{array}$ & $\begin{array}{l}\text { Jatobá-do- } \\
\text { cerrado }\end{array}$ & $\begin{array}{l}\text { A planta é usada como depurativo, antinflamatório, estimulante do apetite } \\
\text { e fortificante rico em ferro (Souza \& Felfili, 2006). A casca do caule e o } \\
\text { epicarpo são utilizados para tratar tosses e anemia e a resina contra sinusite } \\
\text { e espasmos abdominais (Agra et al., 2007). A resina é também peitoral, } \\
\text { tônica, e em maior dose, vermífuga; e a casca é utilizada contra cistites e } \\
\text { prostatites (Ferreira, 1980). A casca e os ramos mais velhos são indicados } \\
\text { para tratar bronquites, tosses, coqueluche, afecções da bexiga e próstata, } \\
\text { sendo adstringente. Os frutos são utilizados como vermífugo (Rodrigues \& } \\
\text { Carvalho, 2001). }\end{array}$ \\
\hline $\begin{array}{l}\text { Inga vera subsp. } \\
\text { affinis (DC.) } \\
\text { T.D.Penn. }\end{array}$ & Ingá & $\begin{array}{l}\text { A casca do caule é utilizada no combate a úlceras externas e feridas } \\
\text { (Rodrigues \& Carvalho, 2010) e contra aftas (Rodrigues \& Carvalho, 2001). }\end{array}$ \\
\hline
\end{tabular}


TABELA 2. Espécies coletadas na área de Cerrado da Fazenda Experimental Santa Rita (FESR), Prudente de Morais, MG, com nome (s) popular (es) e indicação na medicina tradicional

continuação...

\begin{tabular}{|c|c|c|}
\hline $\begin{array}{l}\text { Kielmeyera coriacea } \\
\text { Mart. \& Zucc. }\end{array}$ & Pau-santo & $\begin{array}{l}\text { A casca é considerada tônica e emoliente, sendo utilizada para tratar dores } \\
\text { de dente (Almeida et al., 1998; Silva Júnior, 2005). As folhas possuem } \\
\text { propriedades emolientes (Ferreira, 1980; Rodrigues \& Carvalho, 2001). }\end{array}$ \\
\hline $\begin{array}{l}\text { Lafoensia pacari } \\
\text { A.St.-Hil. }\end{array}$ & $\begin{array}{l}\text { Pacari, } \\
\text { dedaleira, etc. }\end{array}$ & $\begin{array}{l}\text { A casca e as folhas servem como cicatrizante de feridas e para tratar gastrites } \\
\text { e úlceras (Ferreira, 1980; Corrêa, 1984, Silva Júnior, 2005). }\end{array}$ \\
\hline $\begin{array}{l}\text { Leucaena } \\
\text { leucocephala (Lam.) } \\
\text { de Wit }\end{array}$ & Leucena & $\begin{array}{l}\text { O óleo das sementes, em cataplasma, é utilizado para tratar inflamações } \\
\text { externas (Agra et al., 2007). }\end{array}$ \\
\hline $\begin{array}{l}\text { Lithrea molleoides } \\
\text { (Vell.) Engl. }\end{array}$ & $\begin{array}{l}\text { Aroeirinha, } \\
\text { aroeira-brava, } \\
\text { etc. }\end{array}$ & $\begin{array}{l}\text { Sob a forma de extrato alcoólico, decocção ou infusão, é utilizada para o } \\
\text { tratamento de tosse, bronquite, artrite, doenças do sistema digestivo, como } \\
\text { diurético, tranquilizante, hemostático e tônico. Possui também atividades } \\
\text { antimicrobianas, antivirais, citotóxicas e imunomoduladoras (Shimizu et al., } \\
2006 \text { ). }\end{array}$ \\
\hline $\begin{array}{l}\text { Machaerium } \\
\text { acutifolium Vogel }\end{array}$ & $\begin{array}{l}\text { Jacarandá } \\
\text { e bico-de- } \\
\text { papagaio }\end{array}$ & Os frutos são usados como diuréticos e sudoríferos (Silva Júnior, 2005). \\
\hline $\begin{array}{l}\text { Magonia pubescens } \\
\text { A.St.-Hil. }\end{array}$ & Tingui & $\begin{array}{l}\text { As sementes são antissépticas (Brandão, 1991), servem para tratar úlceras, a } \\
\text { casca para feridas e as raízes para os nervos. A resina da casca é inseticida } \\
\text { e utilizada para matar piolhos (Silva Júnior, 2005). }\end{array}$ \\
\hline $\begin{array}{l}\text { Maprounea } \\
\text { brasiliensis A.St.-Hil. }\end{array}$ & $\begin{array}{l}\text { Marmelinho-do- } \\
\text { campo }\end{array}$ & $\begin{array}{l}\text { As cascas das raízes podem ser utilizadas para ativar o apetite e a digestão, } \\
\text { podendo causar vômitos quando ingeridas em grande quantidade devido às } \\
\text { suas propriedades tóxicas (Hoehne, 1939). Seu látex pode ser utilizado como } \\
\text { cicatrizante (Senna, 1989). }\end{array}$ \\
\hline $\begin{array}{l}\text { Marsdenia altissima } \\
\text { (Jacq.) Dugand }\end{array}$ & Cipó-de-leite & $\begin{array}{l}\text { A casca do caule é utilizada para tratar gonorréia, asma e câncer, sendo } \\
\text { utilizada também para aumentar a fertilidade (Agra et al., 2007). }\end{array}$ \\
\hline Mimosa pigra L. & Unha-de-gato & A casca é utilizada como vermífugo (Corrêa, 1984). \\
\hline $\begin{array}{l}\text { Myracrodruon } \\
\text { urundeuva Allemão }\end{array}$ & $\begin{array}{l}\text { Gonçalo-alves, } \\
\text { aroeira, etc. }\end{array}$ & $\begin{array}{l}\text { A casca é utilizada no tratamento das afecções das vias respiratórias e do } \\
\text { aparelho urinário e contra hemorróidas, por suas propriedades balsâmicas e } \\
\text { hemostáticas (Agra et al., 2007). A casca também é utilizada como cicatrizante } \\
\text { e contra inflamações dos ovários, trompas e colo uterino (Souza \& Felfili, } \\
\text { 2006). As folhas são antissépticas, empregadas no tratamento das úlceras, } \\
\text { bronquites e resfriados. As raízes são usadas para tratar o reumatismo. O óleo } \\
\text { extraído dos frutos é utilizado no tratamento da lepra (Almeida et al., 1998). }\end{array}$ \\
\hline $\begin{array}{l}\text { Myriophyllum } \\
\text { aquaticum (Vell.) } \\
\text { Verdc. }\end{array}$ & $\begin{array}{l}\text { Pinheirinho- } \\
\text { d'água }\end{array}$ & É adstringente (Corrêa, 1984). \\
\hline $\begin{array}{l}\text { Myrsine guianensis } \\
\text { (Aubl.) Kuntze }\end{array}$ & Capororoca & $\begin{array}{l}\text { Seus ramos, com folhas são utilizados para tratar picadas de cobra, limpeza } \\
\text { de tumores e feridas (Rodrigues \& Carvalho, 2001; Rodrigues \& Carvalho, } \\
\text { 2010). }\end{array}$ \\
\hline $\begin{array}{l}\text { Myrsine umbellata } \\
\text { Mart. }\end{array}$ & Pororoca-grande & $\begin{array}{l}\text { Seus ramos, com folhas são utilizados para tratar picadas de cobra, tumores } \\
\text { e feridas (Rodrigues \& Carvalho, 2001). }\end{array}$ \\
\hline $\begin{array}{l}\text { Palicourea rigida } \\
\text { Kunth }\end{array}$ & $\begin{array}{l}\text { Douradinha, } \\
\text { congonha-de- } \\
\text { bugre, dom- } \\
\text { bernardo, etc. }\end{array}$ & $\begin{array}{l}\text { A raiz, casca do caule e folhas são indicadas como depurativa, para tratamento } \\
\text { de doenças renais, nas inflamações do aparelho feminino (Rodrigues \& } \\
\text { Carvalho, 2001). As folhas são utilizadas como diurético (Guarim Neto, 1987). }\end{array}$ \\
\hline $\begin{array}{l}\text { Piptocarpha } \\
\text { rotundifolia (Less.) } \\
\text { Baker }\end{array}$ & $\begin{array}{l}\text { Coração- } \\
\text { de-negro, } \\
\text { cartucheira, etc. }\end{array}$ & $\begin{array}{l}\text { As folhas e flores são usadas como enérgicos (Corrêa, 1984) e no combate } \\
\text { à sífilis (Siqueira, 1981). A planta é utilizada também, como antisséptico, } \\
\text { antinflamatório e anti-diarréico (Monteiro et al., 2006) }\end{array}$ \\
\hline
\end{tabular}


TABELA 2. Espécies coletadas na área de Cerrado da Fazenda Experimental Santa Rita (FESR), Prudente de Morais, MG, com nome (s) popular (es) e indicação na medicina tradicional

\begin{tabular}{|c|c|c|}
\hline $\begin{array}{l}\text { Plathymenia } \\
\text { reticulata Benth. }\end{array}$ & Vinhático & $\begin{array}{l}\text { As cascas do caule e ramos são utilizadas para tratar varizes (Guarim Neto, } \\
\text { 1987). }\end{array}$ \\
\hline $\begin{array}{l}\text { Plenckia populnea } \\
\text { Reissek }\end{array}$ & $\begin{array}{l}\text { Marmelinho-do- } \\
\text { campo }\end{array}$ & $\begin{array}{l}\text { O chá dos ramos com folhas é indicado para tratar alergias e feridas (Maroni } \\
\text { et al., 2006) e como antidisentérico (Corrêa, 1984). }\end{array}$ \\
\hline $\begin{array}{l}\text { Qualea grandiflora } \\
\text { Mart. }\end{array}$ & Pau-terra & $\begin{array}{l}\text { As cascas são antissépticas (Ferreira, 1980). As folhas são indicadas para } \\
\text { tratar diarréias com sangue, cólicas intestinais e amebas (Rodrigues \& } \\
\text { Carvalho, 2001; Silva Júnior, 2005). }\end{array}$ \\
\hline $\begin{array}{l}\text { Randia armata (Sw.) } \\
\text { DC. }\end{array}$ & $\begin{array}{l}\text { Espinho-de- } \\
\text { judeu }\end{array}$ & $\begin{array}{l}\text { A casca da raiz é tônica e febrífuga (Corrêa, 1984) e para tratar reumatismo. } \\
\text { O fruto combate cansaço e falta de ar. As folhas e raízes, em decocto, são } \\
\text { usadas para combater gonorréia. As sementes são estimulantes do apetite. } \\
\text { As folhas são cicatrizantes e para tratar doenças inflamatórias (Erbano, 2010). }\end{array}$ \\
\hline $\begin{array}{l}\text { Roupala montana } \\
\text { Aubl. }\end{array}$ & Carne-de-vaca & $\begin{array}{l}\text { A casca do caule é utilizada para tratar feridas e úlceras externas (Rodrigues } \\
\& \text { Carvalho, 2010). }\end{array}$ \\
\hline $\begin{array}{l}\text { Rudgea viburnoides } \\
\text { (Cham.) Benth. }\end{array}$ & $\begin{array}{l}\text { Congonha-de- } \\
\text { bugre }\end{array}$ & $\begin{array}{l}\text { A casca e as raízes são utilizadas para tratamento de reumatismo, gota, } \\
\text { má circulação do sangue e tônico do coração; as folhas são utilizadas } \\
\text { como diuréticas, para tratamento de doenças renais e úlceras (Rodrigues } \\
\text { \& Carvalho, 2001). }\end{array}$ \\
\hline $\begin{array}{l}\text { Schefflera } \\
\text { macrocarpa (Cham. } \\
\text { \& Schltdl.) Frodin }\end{array}$ & $\begin{array}{l}\text { Mandiocão-do- } \\
\text { cerrado }\end{array}$ & As folhas são utilizadas como analgésico (Rodrigues \& Carvalho, 2001). \\
\hline $\begin{array}{l}\text { Sebastiania } \\
\text { brasiliensis Spreng. }\end{array}$ & Pau-leiteiro & $\begin{array}{l}\text { A casca do caule é utilizada no tratamento de amenorréia, leucorréia e como } \\
\text { purgativo e diurético; topicamente é utilizada para tratar dermatites, eczemas, } \\
\text { hidropsia e sífilis (Agra et al., 2007). }\end{array}$ \\
\hline $\begin{array}{l}\text { Smilax brasiliensis } \\
\text { Spreng. }\end{array}$ & Japecanga & $\begin{array}{l}\text { O decocto ou infuso das raízes é utilizado pra tratar afecções da pele e } \\
\text { gota, sendo antissifilítica, anti-reumática, depurativa, diurética e sudorífica } \\
\text { (Rodrigues \& Carvalho, 2001). }\end{array}$ \\
\hline $\begin{array}{l}\text { Solanum } \\
\text { aculeatissimum } \\
\text { Jacq. }\end{array}$ & Juá-bravo & $\begin{array}{l}\text { A planta toda é utilizada para banhos contra infecções cutâneas, edemas } \\
\text { dos membros inferiores e tuberculose mesentérica (Corrêa, 1984). Os frutos } \\
\text { são utilizados em tratamento de manchas de pele e furúnculos (Rodrigues } \\
\text { \& Carvalho, 2001). }\end{array}$ \\
\hline $\begin{array}{l}\text { Solanum lycocarpum } \\
\text { A.St.-Hil. }\end{array}$ & $\begin{array}{l}\text { Lobeira, fruta- } \\
\text { de-lobo, etc. }\end{array}$ & $\begin{array}{l}\text { As folhas, em banho ou compressas, são emolientes e anti-reumáticas. As } \\
\text { flores e frutos são tônicos, contra asma, gripes e resfriados (Rodrigues \& } \\
\text { Carvalho, 2001). }\end{array}$ \\
\hline $\begin{array}{l}\text { Solanum scuticum } \\
\text { M.Nee }\end{array}$ & Jurubeba & $\begin{array}{l}\text { As folhas e frutos são empregados contra problemas hepáticos e digestivos, } \\
\text { por estimular as funções digestivas e reduzir o inchaço do fígado e vesicular } \\
\text { (Mentz \& Oliveira, 2004; Moraes, 2008). }\end{array}$ \\
\hline $\begin{array}{l}\text { Styrax ferrugineus } \\
\text { Nees \& Mart. }\end{array}$ & $\begin{array}{l}\text { Laranjeirinha, } \\
\text { lararanjinha-do- } \\
\text { cerrado, etc. }\end{array}$ & $\begin{array}{l}\text { O ramo com folhas, em infusão, é utilizado como antifebril (Rodrigues \& } \\
\text { Carvalho, 2001). A resina é depurativa, usada no tratamento de queimadura } \\
\text { e tosse (Barros, 1982) e a casca do caule e folhas é depurativo nas febres } \\
\text { (Grandi et al., 1989). }\end{array}$ \\
\hline $\begin{array}{l}\text { Tabebuia aurea } \\
\text { (Silva Manso) Benth. } \\
\text { \& Hook f. ex S. } \\
\text { Moore }\end{array}$ & Ipê-amarelo & $\begin{array}{l}\text { A casca do caule é usada contra gripes, bronquites e inflamações (Agra et } \\
\text { al., 2007) sendo febrífuga e depurativa. As raízes também são utilizadas para } \\
\text { tratar gripes, resfriados e tosses (Rodrigues \& Carvalho, 2001). }\end{array}$ \\
\hline $\begin{array}{l}\text { Tapirira guianensis } \\
\text { Aubl. }\end{array}$ & Pau-pombo & $\begin{array}{l}\text { A casca e as folhas, em decocto, são indicadas para dermatoses e também } \\
\text { como antissifilítico e depurativo (Rodrigues \& Carvalho, 2001). }\end{array}$ \\
\hline $\begin{array}{l}\text { Tarenaya spinosa } \\
\text { (Jacq.) Raf. }\end{array}$ & Sete-marias & As folhas são usadas contra asma, tosse e bronquite (Agra et al., 2007). \\
\hline
\end{tabular}


TABELA 2. Espécies coletadas na área de Cerrado da Fazenda Experimental Santa Rita (FESR), Prudente de Morais, MG, com nome (s) popular (es) e indicação na medicina tradicional

\begin{tabular}{l|l|l}
\hline $\begin{array}{l}\text { Terminalia argentea } \\
\text { Mart. }\end{array}$ & Capitão & $\begin{array}{l}\text { A casca do tronco, em decocção, é utilizada para tratar aftas e tumores como } \\
\text { resolutivo (Ferreira, 1980). }\end{array}$ \\
\hline $\begin{array}{l}\text { Tocoyena formosa } \\
\text { (Cham. \& Schltdl.) } \\
\text { K.Schum. }\end{array}$ & $\begin{array}{l}\text { Jenipapo-de- } \\
\text { cavalo }\end{array}$ & $\begin{array}{l}\text { A casca da raiz tem ação tônica e febrífuga (Corrêa, 1984). É utilizada para } \\
\text { o tratamento de dores reumáticas (Coelho et al., 2006). }\end{array}$ \\
\hline $\begin{array}{l}\text { Vernonanthura } \\
\text { phosphorica (Vell.) } \\
\text { H.Rob. }\end{array}$ & Assa-peixe & $\begin{array}{l}\text { A planta toda é utilizada como antifebril, em bronquites, pneumonias, gripes } \\
\text { e tosses (Rodrigues \& Carvalho, 2001). }\end{array}$ \\
\hline $\begin{array}{l}\text { Xylopia aromatica } \\
\text { Lam.) Mart. }\end{array}$ & Pimenta-de- & $\begin{array}{l}\text { A casca do caule é utilizada como antinflamatório (Rodrigues \& Carvalho, } \\
\text { 2001). Os frutos são utilizados como excitante, carminativo, afrodisíaco, } \\
\text { tônico para o estômago, vermífugo, febrífugo e anti-hemorroidal (Corrêa, } \\
1984, \text { Brandão, 1991; Rodrigues \& Carvalho, 2001). }\end{array}$ \\
\hline $\begin{array}{l}\text { Zeyheria montana } \\
\text { Mart. }\end{array}$ & Bolsa-de-pastor & $\begin{array}{l}\text { A casca da raiz é utilizada para tratar afecções da pele e a casca do caule } \\
\text { é antissifilítica (Rodrigues \& Carvalho, 2001). }\end{array}$ \\
\hline
\end{tabular}

levar em consideração que estas duas famílias, são as mais diversas das Angiospermas (Souza \& Lorenzi, 2012). A família Fabaceae possui grande número de espécies que são alimentícias, medicinais, ornamentais, madeireiras, etc. (Di Stasi et al., 2002). Espécies de Fabaceae, do gênero Bauhinia se destacam pelas suas propriedades medicinais, sendo utilizadas como fitoterápicas para o tratamento de várias enfermidades, principalmente diabetes, processos dolorosos e infecções (Teske \& Trentini, 1995). No entanto, para B. brevipes Vogel, espécie encontrada na FESR, não há citações de uso medicinal. Dentre as leguminosas medicinais, quatro (D. mollis Benth., $H$. stigonocarpa Mart ex Hayne, I. vera subsp. affinis (DC.) T.D.Penn. e $L$. leucocephala (Lam.) de Wit) são indicadas como cicatrizante, adstringente e ou antinflamatório, o que pode indicar a presença de taninos, compostos responsáveis pelas adstringência e atividades farmacológicas (Santos \& Mello, 2004). Dentre as seis espécies de Rubiaceae encontradas na Reserva, cinco são utilizadas como medicamento. Segundo Di Stasi \& Hiruma Lima (2002), essa família possui muitos gêneros que incluem espécies de valor medicinal, entre eles destacam-se Coffea e Cinchona, fontes de substâncias como a cafeína e o quinino, respectivamente, de amplo uso terapêutico. Espécies de Palicourea e Psychotria, ambos, gêneros de Rubiaceae, são conhecidas popularmente como "mata-ratos", sendo consideradas venenosas (Coelho et al., 2006).

As espécies que apresentaram mais finalidades terapêuticas (Tabela 2) foram: $B$. gaudichaudii Trécul, C. brasiliense Cambess., C. regium (Mart. ex Schrank) Pilg., C. urucurana Bail., G. officinalis Mart., H. stigonocarpa Mart. ex Hayne, L. molleoides (Vell.) Engl., M. urundeuva Allemão e R. armata (Sw.) DC. o que sugerem a existência de um rico metabolismo secundário, podendo haver princípios ativos de diferentes classes químicas em cada espécie. B. gaudichaudii tem sido usada em escala industrial para a obtenção de medicamentos. Segundo Palhares \& Silveira (2007), o uso medicinal da espécie é consequência do grande acúmulo, nas raízes, de furanocumarinas, como o bergapteno e o psolareno. Pozetti (2005) comenta que $B$. gaudichaudii é uma dádiva da natureza que devemos aproveitar antes que tenhamos que pagar royalties por um produto oriundo dela, mas desenvolvido por outro país. C. brasiliense tem grande quantidade de carotenóides (Azevedo-Meleiro \& RodriguezAmaya, 2004) e possui atividade antifúngica sobre Cryptococcus neoformans (Passos et al., 2002).

A espécie $C$. regium deve ser utilizada com cautela como medicamento, até que se obtenham mais dados sobre sua toxicidade, sendo necessários mais estudos tecnológicos para sua utilização segura (Sólon et al., 2009). O látex de C. urucurana possui saponinas, esteróides, alcalóides, antocianidinas e catequinas. Algumas destas substâncias podem exercer efeito anti-diarréico, uma vez que estes compostos precipitam proteínas dos enterócitos e reduzem os movimentos peristálticos (Okuda et al., 1989; Gabriel et al., 1999). Segundo estudos fitoquímicos, os principais constituintes químicos desta planta têm atividade antioxidante como os taninos e lignanas, além do alcaloide taspina, que atua como antinflamatório (Perdue et al, 1979; Vaisberg et al., 1989), corroborando sua utilização na medicina popular. Nos xilopódios de G. officinalis há saponinas e ecdisterona (Young et al., 1992). A ecdisterona é utilizada pela indústria farmacêutica para a produção de fitoterápicos e suplementos alimentares (Magalhães, 2000). Segundo Rodrigues

Rev. Bras. PI. Med., Campinas, v.17, n.4, supl. III, p.1016-1030, 2015. 
et al. (2012), as indicações medicinais de $H$. stigonocarpa podem estar associados com o efeito antioxidante de taninos condensados e flavonóides, assim como os efeitos antinflamatórios e antiulcerativos de $M$. urundeuva estão relacionados com os taninos presentes nas cascas do caule (Souza et al., 2007). As propriedades antinflamatórias de L. molleoides, foram confirmadas por estudos realizados com ratos (Gorzalczany et al., 2011). $\mathrm{Em} R$. armata foram identificadas catequinas, esteróides, flavonas, taninos catéquicos e xantonas que estão relacionados com a atividade antioxidante (Vieira et al., 2005).

As indicações terapêuticas citadas foram: tônico, incluindo tônico para o coração e para o estômago, fortificante, enérgico e para tratamento da debilidade geral do organismo (15 spp., 22,7\%); de afecções do aparelho respiratório, incluindo tosse, gripe, resfriado, bronquites e asma (13 spp., 19,6\%); de afecções da pele, incluindo manchas, dermatites, dermatoses, eczemas, queimaduras e vitiligo (12 spp., 18\%); de febres (12 spp.); como antinflamatório, incluindo inflamações intestinais, uterinas, dos ovários, trompas e inflamações externas (11 spp., 16\%), tratamento e limpeza de feridas e úlceras, como antisséptico (11 spp.); antisséptico e cicatrizante (2 spp., $3 \%$ ); cicatrizante (4 spp., 6\%); antisséptico (2 spp.); diurético (9 spp., 13,6\%); depurativo (8 spp., 12\%); tratamento de diarréias, incluindo anti-disentéricas (8 spp.); anti-reumáticas (7 spp.); adstringentes (7 spp., $10,6 \%$ ); analgésico, incluindo as utilizadas para tratar dores de cabeça, de dente, no corpo e por quedas (5 spp., 7,6\%); tratamento de hemorróidas (5 spp.); antissifilítica (4 spp.); purgante (4 spp); laxante (4 spp.); tratamento de doenças renais e das vias urinárias (4 spp.); de problemas intestinais, incluindo colites e enterites (4 spp.); má digestão (4 spp.); colagogo (1 sp.); tratamento dos problemas de fígado, incluindo inchaço e hepatite (4 spp.); calmante (3 spp., 4,5\%); tratamento de picadas de cobra (3 spp.); de tumores (3 spp.); inseticidas e ou insetífugas ( $3 \mathrm{spp}$.); estimulante do apetite (3 spp.); tratamento de alergias (2 spp.); amenorréia (2 spp.); gonorréia (2 spp.); aftas (2 spp.); e antiespasmódicas (2 spp.). As indicações de tratamento da hipercolesterolemia, cardiopatia, varizes, má circulação do sangue, gastrite, oftalmia, leucorréia, amebíase, linfatismo, orquites, sinusite, problemas da próstrata, edemas dos membros inferiores, tuberculose mesentérica, furúnculos e lepra; remoção de verrugas, leishmaniose, anestésico, antiviral, estimulante do sistema nervoso central, causadora de contrações uterinas, carminativo e piolhicida também foram citadas para pelo menos uma espécie.

O conhecimento da medicina tradicional, principalmente relacionado ao uso de plantas silvestres está desaparecendo rapidamente devido à modernização e mudanças nos estilos de vida (Agra et al., 2007) e às transfomações ocorridas no Cerrado (Klink \& Moreira, 2002; Henriques, 2003; Klink \& Machado, 2005), por isso há uma necessidade urgente de se conhecer os usos de plantas nativas como remédios, incentivando a conservação e verificação científica de plantas medicinais raras e menos conhecidas (Maroni et al., 2006; Agra et al., 2007).

Quanto ao estado de conservação, Chresta sphaerocephala (Asteraceae) e Myhracrodruon urundeuva Allemão (Anacardiaceae), ambas coletadas na área, encontram-se na lista das espécies da flora ameaçadas de extinção, em Minas Gerais, incluídas na categoria vulnerável (Drummond et al., 2008).

\section{AGRADECIMENTO}

À Fundação de Amparo à Pesquisa do Estado de Minas Gerais (FAPEMIG), pelo financiamento do projeto APQ-03738-10 e pelas bolsas concedidas às autoras.

\section{REFERÊNCIAS}

AGRA, M. et al. Synopsis of the plants known as medicinal and poisonous in Northeast of Brazil. Revista Brasileira de Farmacognosia, v.17, n.1, p.114-140, 2007.

ALMEIDA, S.P. et al. Cerrado: espécies vegetais úteis. Planaltina: EMBRAPA/CPAC, 1998, 464p.

ARANTES, A.A. et al. O uso de plantas medicinais no município de Itumbiara, Goiás, Brasil. Práxis, n.3, p. 43-56, 2003.

AZEVEDO-MELEIRO, C.H.; RODRIGUEZ-AMAYA, D.B. Confirmation of the identity of the carotenoids of tropical fruits by HPLC-DAD and HPLC-MS. Journal of food Composition and Analysis, v.17, n.3-4, p.385-396, 2004.

BARBOSA, W.L.R. et al. Documentação e valorização da fitoterapia tradicional Kayapó nas aldeias A'Ukre e Pykanu - sudeste do Pará. Revista Brasileira de Farmacognosia, v.14, supl.1, p-47-49, 2003.

BARROS, M.A.G. Flora medicinal do Distrito Federal. Brasil Florestal, v.12, n.50, p.35-45, 1982.

BRANDÃO, M. et al. Guia ilustrado de plantas do Cerrado de Minas Gerais. Belo Horizonte: CEMIG, 1992, 78p.

BRANDÃO, M. et al. Guia ilustrado de plantas do cerrado de Minas Gerais: caracterização, floração, frutificação, propagação e utilização de 30 plantas do Cerrado brasileiro. São Paulo: Nobel, 2001. 96p.

BRANDÃO, M. Plantas medicamentosas do cerrado mineiro. Informe Agropecuário, v.15, n.168, p.15-20, 1991.

BRASIL. Ministério do Meio Ambiente. Conselho de 
Gestão do Patrimônio Genético. Brasília, [2014]. Disponível em: <http://www.mma.gov.br/patrimoniogenetico/conselho-de-gestao-do-patrimonio-genetico>. Acesso em: 29 abr. 2014.

CALIXTO, J.B. Biopirataria: A diversidade biológica na mira da indústria farmacêutica. Ciência Hoje, v.28, n.167, p.36-43, 2000.

CASTRO, A.A.J.F. et al. How rich is the flora of Brasilian Cerrados? Annals of the Missouri Botanical Garden, Saint Louis, v.86, n.1, p.192-224, 1999.

COELHO, V.P.M. et al. Estudo farmacobotânico das folhas de Tocoyena formosa (Cham. \& Schltdl.) K. Schum. (Rubiaceae). Revista Brasileira de Farmacognosia, v.16, n.2, p.170-177, 2006.

CORREAA, P.C. Dicionário das plantas úteis do Brasil e das exóticas cultivadas. Rio de Janeiro: Imprensa Nacional, 1984, 6v.

DI STASI, L.C. et al. Fabales medicinais. In: DI STASI, L.C.; HIRUMA-LIMA, C.A. Plantas medicinais na Amazônia e na Mata Atlântica. 2 ed. São Paulo: UNESP, 2002. cap.18, p.276-320.

DI STASI, L.C.; HIRUMA-LIMA, C.A. Rubiabales medicinais. In: DI STASI, L.C.; HIRUMA-LIMA, C.A. Plantas medicinais na Amazônia e na Mata Atlântica. 2 ed. São Paulo: UNESP, 2002. cap.29, p.492-495.

DRUMMOND, G.M. et al. (Ed.). Listas Vermelhas das Espécies da Fauna e da Flora Ameaçada de Extinção em Minas Gerais. 2.ed. Belo Horizonte: Fundação Biodiversitas, 2008. (CD Rom).

DRUMMOND, G.M. et al. (Org.). Biodiversidade em Minas Gerais: um atlas para sua conservação. 2.ed. Belo Horizonte: Fundação Biodiversitas, 2005. 222p.

EHRLICH, P.R. A perda da diversidade: causas e conseqüências. In: WILSON, E.O. (Org.). Biodiversidade. Rio de Janeiro: Nova Fronteira, 1997. p.27-35.

ERBANO, M. Morfoanatomia de folha e caule das espécies Centrolobium tomentosum Guillemin ex Benth. (Fabaceae), Genipa americana L. e Randia armata (Sw.) DC. (Rubiaceae). 2010. 81f. Dissertação (Mestrado em Ciências Farmacêuticas) - Universidade Federal do Paraná, Curitiba, 2010.

FERREIRA, M.B. Plantas portadoras de substâncias medicamentosas, de uso popular, nos cerrados de Minas Gerais. Informe Agropecuário, v.6, n.61, p.1923, 1980.

FIDALGO, O.; BONONI, V.L. Técnicas de coleta, preservação e herborização de material botânico. São Paulo: Instituto de Botânica, Série Documentos, 1984, 62p.

GABRIEL, S.E. et al. A novel plant-derived inhibitor of cAMP-mediated fluid and chloride secretion. American Journal of Physiology, v.276, n.1, part 1, G58-63, 1999.

GIULIETTI, A.M. et al. Biodiversidade e conservação das plantas no Brasil. Megadiversidade, v.1, n.1, p.52-61, 2005.

GORZALCZANY, S. et al. Anti-inflammatory effect of Lithrea molleoides extracts and isolates active compounds. Journal of Ethnopharmacology, v.133, n.3, p.994-998, 2011.

GRANDI, T.S.M. et al. Plantas medicinais de Minas Gerais, Brasil. Acta Botanica Brasilica, v.3, n.2, supl., p.185224, 1989.
GUARIM NETO, G. MORAIS, R.G. Recursos medicinais de espécies do Cerrado de Mato Grosso: um estudo bibliográfico. Acta Botanica Brasilica, v.17, n.4, p.561584, 2003.

GUARIM NETO, G. Plantas utilizadas na medicina popular no Estado de Mato Grosso. Brasília: CNPq, 1987, 58p.

HENRIQUES, R.P.B. O futuro ameaçado do Cerrado brasileiro. Ciência Hoje, v.33, n.195, p.34-39, 2003.

HOEHNE, F.C. Plantas e substâncias tóxicas e medicinais. São Paulo: Graphicars, 1939. 180p.

JARDIM BOTÂNICO DO RIO DE JANEIRO. Lista de Espécies da Flora do Brasil. Rio de Janeiro, 2013. Disponível em: <http://floradobrasil.jbrj.gov.br/>. Acesso em: 2 mar. 2015.

KLINK, C.A.; MACHADO, R.B. A conservação do Cerrado brasileiro. Megadiversidade, v.1, n.1, p.147-155, 2005.

KLINK, C.A.; MOREIRA, A.G. Past and current human occupation and land-use. In: OLIVEIRA, P.S.; MARQUIS, R.J. (Eds.) The Cerrado of Brazil. Ecology and natural history of a neotropical savanna. New York: Columbia University Press. 2002. p.69-88.

KUHLMANN, M. Frutos e sementes do cerrado atrativos para a fauna: guia de campo. Brasília: Rede de Sementes do Cerrado, 2012, 360p.

LEITÃO, S.G. et al. Sterols and sterol glucosides from two Aegiphila species. Phytochemistry, v.31, p. 28132817, 1992.

LORENZI, H.; MATOS, F.J.A. Plantas medicinais no Brasil: nativas e exóticas. 2.ed. Nova Odessa: Instituto Plantarum, 2008. 544p.

MAGALHÃES, P.M. Agrotecnologia para el cultivo de fáfia o gingeng brasileiro. In: MARTINEZ, J.V. et al. (Eds.). Fundamentos de agrotencología de cultivo de plantas medicinales iberoamericanas. Santafé de Bogotá: Convênio Andrés Bello/CYTED, 2000, p.323-332.

MARONI, B. C.; et al. Plantas medicinais do cerrado de Botucatu: guia ilustrado. São Paulo: UNESP, 2006. $194 p$.

MARTINS, C.S. Caracterização física e fitogeográfica de Minas Gerais. In: MENDONÇA, M.P.; LINS, L.V. Lista vermelha das espécies ameaçadas de extinção da flora de Minas Gerais. Belo Horizonte: Fundação Biodiversitas, Fundação Zoo-Botânica de Belo Horizonte, p.35-43, 2000.

MATTEUCCI, M.B.A. et al. A flora do cerrado e suas formas de aproveitamento. Anais da Escola de Agronomia e Veterinária, v.25, n.1, p.13-30, 1995.

MENDONÇA, R.C. et al. Flora vascular do cerrado. In: SANO, S. M.; ALMEIDA, S. P. (Eds.). Cerrado: Ambiente e flora. Planaltina: EMBRAPA/CPAC. cap.7. p.289-539. 1998.

MENTZ, L. A; OLIVEIRA, P. L. Pesquisas. Solanum (Solanaceae) na região sul do Brasil. São Leopoldo: Unisinos, n. 54, 2004, 327 p.

MONTEIRO, J.M. et al. Use patterns and knowledge of medicinal species among two rural communities in Brazil's semi-arid northeastern region. Journal of Ethnopharmacology, v.105, p.173-86, 2006.

MORAES, L.U. Identificação e descrição morfoanatômica e farmacognóstica das folhas de Solanum scuticum M. Nee e bioatividade de extrato 
bruto em microrganismos e da fração alcaloídica em células cultivadas da Linhagem Vero. 2008. $98 \mathrm{f}$. Dissertação (Mestrado em Biologia) - Universidade Federal de Goiás, Curitiba, 2008.

OKUDA, T. et al. New methods of analyzing tannins. Journal of Natural Products, v.52, n.1, p.1-31, 1989. OLIVEIRA-FILHO, A.T. et al. Estudos florísticos e fitossociológicos em remanescentes de matas ciliares do Alto e Médio Rio Grande. Belo Horizonte: CEMIG, 1995. (Boletim técnico 11. 106-MA/PA-013).

PALHARES, D.; SILVEIRA, C.E.S. Aspectos morfológicos de plantas jovens de Brosimum gaudichaudii Tréc. (Moraceae) produzidas em condições alternativas de cultivo. Revista Brasileira de Plantas Medicinais, v.9, n.1, p.93-96, 2007.

PASSOS, X.S. et al. Atividade antifúngica de Caryocar brasiliensis (Caryocaraceae) sobre Cryptococcus neoformans. Revista da Sociedade Brasileira de Medicina Tropical, v.35, n.6, p.623-627, 2002.

PAVAN, F.R. et al. Evaluation of anti-Mycobacterium tuberculosis activity of Campomanesia adamantium (Myrtaceae). Química Nova, v.32, n.5, p.1222-1226, 2009.

PEIXOTO, A.L.; MORIM, M.P. Coleções botânicas: documentação da biodiversidade brasileira. Ciência e Cultura, v.55, n.3, p.21-24, 2003.

PENNA, M. Dicionário brasileiro de plantas medicinais: descrição das plantas medicinais indígenas e das exóticas aclimadas do Brasil. Rio de Janeiro: Kosmos, 1946. 409p.

PERDUE, G.P. South American plants II: taspine isolation and anti-inflammatory activity. Journal of Pharmaceutical Science, v.68, n.1, p.124-126, 1979.

POZETTI, G.L. Brosimum gaudichaudii Trecul (Moraceae): da planta ao medicamento. Revista de Ciências Farmacêuticas Básica e Aplicada, v.26, n.3, p.159166, 2005

RATTER, J.A. et al. The Brazilian cerrado vegetation and threats to its biodiversity. Annals of Botany, v.80, p.223-230, 1997.

RIZZINI, C.T.; MORS, W.B. Botânica econômica brasileira. 2 ed. Rio de Janeiro: Âmbito Cultural, 1995, $241 \mathrm{p}$.

RODRIGUES, O.P. et al. Hymenaea stigonocarpa Mart. ex Hayne: a brazilian medicinal plant with gastric and duodenal anti-ulcer and antodiarrheal effects in experinental rodent models. Journal of Ethnopharmacology, v.143, n.1, p.81-90, 2012.

RODRIGUES, V.E.G.; CARVALHO, D.A. Plantas medicinais nas florestas semideciduais. Lavras: UFLA, 2010, 128p.

RODRIGUES, V.E.G.; CARVALHO, D.A. Plantas medicinais no domínio dos cerrados. Lavras: UFLA, 2001, 180p.

SANTOS, S.C.; MELLO, J.C.P. Taninos. In: SIMÕES, C.M.O. et al. (Org.). Farmacognosia: da planta ao medicamento. 5 ed. Porto Alegre: UFRGS, Florianópolis: UFSC. cap. 24, p.615-656, 2004.

SENNA, L.M. Maprounea Aubl. (Euphorbiaceae). Considerações taxonômicas e anatômicas das espécies sul-americanas. Rodriguésia, v.36, n.61, p.51-78, 1989.

SHEPHERD, G.J. Avaliação do estado do conhecimento da diversidade biológica do Brasil: plantas terrestres
- versão preliminar. Brasília: Ministério do Meio Ambiente, 2003. 60p. Disponível em: <http://www.mma. gov.br/estruturas/chm/_arquivos/plantas1>. Acesso em: 28 abr. 2014.

SHIMIZU, M. T. et al. Essential oil of Lithraea molleoides (Vell.): chemical composition and antimicrobial activity. Brazilian Journal of Microbiology, São Paulo, v.37, n.4, p.556-560, 2006.

SILVA JÚNIOR, M.C.S. 100 Árvores do Cerrado: guia de Campo. Brasília: Rede de Sementes do Cerrado, 2005, 278p.

SILVA, V.C. et al. A new antifungal phenolic glycoside derivative iridoids and libgnans from Alibertia sessilis (Vell.) K. Schum. (Rubiaceae). Journal of Brazilian Chemical Society, v.18, n.7, p.1405-1409, 2007.

SIQUEIRA, J.C. Utilização popular das plantas do Cerrado. São Paulo: Loyola, 1981, 60p.

SÓLON, S. et al. O gênero Cochlospermum Kunth com ênfase nos aspectos etnobotânicos, farmacológicos, toxicológicos e químicos de Cochlospernum regium (Mart. et Schr.) Pilger. Revista Eletrônica de Farmácia, v.4, n.3, p.1-22, 2009.

SOUZA, C.D; FELFILI, J.M. Uso de plantas medicinais na região de Alto Paraíso de Goiás, GO, Brasil. Acta Botânica Brasilica, v.20, n.1, p.135-142, 2006.

SOUZA, S.M. et al. Antiinflammatory and antiulcer properties of tannins from Myracrodruon urundeuva Allemão (Anacardiaceae) in rodents. Phytotherapy Research, v.21, n.3, p.220-225, 2007

SOUZA, V.C.; LORENZI, H. Botânica sistemática: guia ilustrado para identificação das famílias de fanerógamas nativas e exóticas no Brasil, baseado em APG III. 3.ed. Nova Odessa: Instituto Plantarum, 2012, 768p.

TESKE, M.; TRENTINI, A.M.M. Compêndio de fitoterapia. Curitiba: Herbarium Laboratório Botânico, 1995, 317p.

VAISBERG, A.J. et al. Taspine is the cicatrizant principle ins Sangre de Grado extracted from Croton lechleri. Planta Medica, v.55, n.2, p.140-143, 1989

VALENTE, M.C.; SILVA, N.M.F. (Org.). Plantas úteis das áreas do entorno do Jardim Botânico do Rio de Janeiro, Horto Florestal Parque Lage - I. Rio de Janeiro: MMA/Jardim Botânico do Rio de Janeiro, Horto, 1999, 80p. (Série Estudos e Contribuições, 16).

VIDAL, W.N.; VIDAL, M.R.R. Botânica - Organografia. 3. ed. Viçosa: UFV, 1986, 114p.

VIEIRA, M.G.S. et al. Estudo fitoquímico e atividade antioxidante dos extratos de plantas do Parque Botânico do Ceará. In: REUNIÃO ANUAL DA SBPC, 57, 2005, Fortaleza. Anais eletrônicos... Fortaleza: SBPC, 2005. Disponível em: <http://www.sbpcnet.org.br/livro/57ra/ programas/SENIOR/RESUMOS/resumo_3492.html>. Acesso em: 9 mar.2015.

VIEIRA, R.F.; MARTINS, M.V.M. Resursos genéticos de plantas medicinais do cerrado: uma compilação de dados. Revista Brasileira de Plantas Medicinais, v.3, n.1, p13-36, 2000.

WILSON, E.O. A situação atual da diversidade biológica. In: WILSON, E.O. (Org.). Biodiversidade. Rio de Janeiro: Nova Fronteira, 1997, p.3-24.

YOUNG, M.C.M. et al. Ecdysterone and saponins from tuberous roots of Gomphrena officinalis Mart. (Amaranthaceae). Revista Latinoamericana de Química, v.23, p.41-44, 1992.

Rev. Bras. PI. Med., Campinas, v.17, n.4, supl. III, p.1016-1030, 2015. 